\title{
ENTRE O AMOR AO ANIMAL E A SAÚdE PÚBLICA: REFLEXÕES SOCIOLÓGICAS SOBRE A LEISHMANIOSE VISCERAL CANINA
}

\author{
Márcia GRISOTTI* \\ Lucas de Carvalho de AMORIM**
}

\begin{abstract}
RESUMO: Os animais sempre fizeram parte das sociedades humanas, seja como fonte de alimento, entidades sagradas, companhias ou mercadorias. Dentre as vertentes de estudos sobre as relações humanos e animais não humanos, este artigo focaliza um aspecto pouco investigado pelas ciências sociais: a dimensão social das políticas de controle das doenças transmitidas entre humanos e animais (doenças zoonóticas). Analisamos as controvérsias e conflitos que ocorrem entre as medidas sociotécnicas adotadas pelos serviços de vigilância epidemiológica para o controle dessa doenças e os significados atribuídos para este controle pelos profissionais de vigilância de zoonoses e pelos meios de comunicação, tendo como estudo de caso as ações públicas de controle da leishmaniose visceral canina desenvolvidas em Florianópolis-SC entre 2010 e 2020. Um dos fatores para a baixa efetividade das políticas públicas de controle está relacionada à falta de articulação entre fatores epidemiológicos e sociais (relacionados às famílias multiespécies) nas campanhas preventivas.
\end{abstract}

PALAVRAS-CHAVE: Famílias multiespécies. Leishmaniose visceral canina. Vigilância em saúde. Saúde humana e animal.

"Deçue par les humanais, jamais pour mon chien."

\footnotetext{
* UFSC - Universidade Federal de Santa Catarina. Programa de Pós-graduação em Sociologia e Ciência Política. Florianópolis - SC - Brasil. 88040-900 - marcia.grisotti@ufsc.br - https://orcid.org/0000-00030389-7100.

** UFSC - Universidade Federal de Santa Catarina. Curso de Ciências Sociais. Florianópolis - SC - Brasil. 88.040-900 - lucasamorim0@gmail.com - https://orcid.org/0000-0001-74136195.
} 
Introdução

Esta frase está escrita na lápide do túmulo de um cachorro enterrado, entre centenas de outros, no Cimetière des Chiens, localizado em Asnières-sur-Seine, na parte noroeste de Paris. Seja pela sua dimensão temporal (o cemitério existe desde 1899), seja pela dimensão qualitativa das frases e rituais dedicados pelos seus antigos proprietários aos seus animais de estimação, este cemitério ilustra as relações históricas de interdependência entre humanos e animais não humanos. Durante a visita e o registro fotográfico, conversamos com uma mulher que estava sepultando seu cachorro. Em meio à preparação dos ornamentos que seriam colocados no túmulo, ela mostrava as fotos enroladas em plásticos que ali seriam deixadas e relatava, em prantos, os diversos momentos felizes que passaram juntos e a tristeza da partida "mais sofrida que a morte de minha mãe".

Os animais sempre fizeram parte das sociedades humanas, seja como fonte de alimento, entidades sagradas, companhias ou mercadorias. Embora as análises sociológicas sobre as relações humanos-animais não humanos ainda sejam incipientes, um campo robusto de pesquisas tem sido reconfigurado para encaixar os não humanos nas análises dos fenômenos sociais. A antropologia, mais do que outras áreas das ciências sociais, tem estudado essas relações devido, sobretudo, à sua tradição de investigações etnográficas com povos indígenas e tradicionais, em que concepções animistas interagem com explicações científicas, e à forte tendência de alguns estudos em problematizar a clássica dicotomia entre cultura e natureza (DESCOLA, 2003, 2011; INGOLD, 1995, 2000, 2005). O trabalho de Ingold expressa uma intenção de ir além dessa dicotomia, incorporando a análise dos organismos vivos conectados aos seus ambientes como uma zona de interpenetração (PITROU, 2015).

Gaedkte (2017) analisa como os cuidados humanos nos processos de adoecimento, envelhecimento e/ou morte de cães e gatos são reveladores de papéis sociais, dos humanos e dos não humanos, bem como de transformações nas configurações familiares no cenário das sociedades urbanas contemporâneas a partir da noção de famílias multiespécies. A autora também reflete, com base em uma extensa revisão bibliográfica, as razões por trás de um certo silenciamento acerca do estudo das relações entre humanos e seus animais de estimação no interior das agendas consagradas de pesquisas sociológicas.

Não pretendemos expor as diversas abordagens e perspectivas deste campo temático, mas dar visibilidade a uma vertente de estudo pouco investigada nos estudos socioantropológicos sobre as relações humanos e animais não humanos: as doenças zoonóticas. Embora isso possa ser óbvio para os pesquisadores no campo da biologia, a 
pandemia de Covid-19 provavelmente estimulará novos estudos interdisciplinaressobre os impactos sociais das doenças emergidas de patógenos que cruzam as barreiras entre as espécies (spillover), fenômeno que exige a inclusão das relações entre comportamentos humanos-animais-natureza na noção de interdependência (ELIAS, 1999), pensada originalmente para pessoas e grupos sociais.

De forma instrumental, diversos tipos de animais têm sido utilizados como modelos experimentais para a construção do conhecimento de doenças humanas. Ao mesmo tempo, alguns animais se beneficiam, como pacientes, da produção de conhecimentos e das tecnologias humanas. Animais de estimação, em perspectivas ambivalentes, são percebidos ora como fonte potencial para a saúde humana ora como fonte potencial de transmissão de doenças infecciosas (ROCK; MYKHALOVSKIY; SCHLICH, 2007).

Uma vez que os estudos específicos sobre as doenças compartilhadas entre humanos e animais são incipientes no campo da sociologia, é através dos conceitos de biossegurança e biopolítica, conectados à gestão de riscos, que encontramos pistas para esta análise. Esses conceitos têm fomentado as investigações relacionadas à multiplicidade de crises sanitárias causadas por doenças transmitidas entre humanos e animais (zoonoses), as quais têm conduzido a uma reformulação das normas e políticas públicas de controle da população animal. As transformações sociotécnicas e políticas em matéria de gestão de doenças infecciosas emergentes (COLLIER; LAKOFF; RABINOW, 2004), bem como os fatores sociais envolvidos no sistema de rastreabilidade, triagem e pesquisa de população animal sentinela, que permite lançar alertas em caso de emergência de novos patógenos (KECK, 2020), são exemplos de uma área de pesquisa promissora nas ciências sociais.

No âmbito deste último enquadramento (BATESON, 1987; GOFFMAN, 1986), visando dar sentido a eventos e vulnerabilidades especiais a que esses quadros de referência estão sujeitos, este artigo pretende interpretar as possíveis causas sociais para a ineficácia do programa brasileiro de controle da leishmaniose visceral canina (LVC). Tal interpretação se dará a partir da análise das controvérsias e conflitos que ocorrem entre as medidas sociotécnicas adotadas pelos serviços de vigilância epidemiológica para o controle dessa doença e os significados atribuídos para este controle pelos profissionais de vigilância de zoonoses e pelos meios de comunicação, tendo como estudo de caso as ações públicas de controle da LVC desenvolvidas em FlorianópolisSC entre 2010 e 2020. Para tanto, foram analisados os documentos oficiais da Organização Mundial da Saúde (OMS), do Ministério da Saúde e os relatórios publicados pelo Centro de Controle de Zoonoses (CCZ) do município de Florianópolis$\mathrm{SC}$, além da realização de pesquisa hemerográfica e de entrevistas com profissionais do 


\section{Vigilância de doenças transmitidas entre humanos e animais não humanos}

Embora os parasitas - e sua associação com humanos - sejam conhecidos e descritos desde a antiguidade clássica e até muito mais tarde, no século XVIII, quando Jenner já havia reconhecido a relação entre infecção de vacas e varíola humana, a medicina permaneceu independente das doenças de outros animais e plantas. A disseminação do processo empírico da varíola na Ásia, Europa e América não reduziu a distância entre o homem e outros animais. A semelhança de certas estruturas e funções comuns a plantas e animais teria sido reconhecida apenas no início do século XIX. Isso se deve à posição privilegiada que o ser humano tem dado à sua espécie, pois vários séculos se passaram até que aceitasse sua origem comum e suas relações com outros organismos da natureza (ÁVILA-PIRES, 2005).

A biologia e a paleontologia são algumas das áreas do conhecimento científico que exploram os vínculos entre a emergência de micróbios, o papel de reservatórios e vetores e a história humana (CRAWFORD, 2007). Por outro lado, as pesquisas na área da epidemiologia e das ciências sociais investigam a relação entre o comércio e a rápida circulação de pessoas, animais, plantas, micro-organismos e mercadorias e a disseminação de patógenos em escala global, bem como as estratégias políticas de controle desenvolvidas em vários setores da sociedade.

A contínua expansão das terras agrícolas para áreas selvagens, o contato com gado e animais domésticos, o boom do tráfico de gado e da produção global têm sido responsáveis pelo surgimento de doenças zoonóticas emergentes em várias regiões do país e do mundo. O relatório da Organização das Nações Unidas para Alimentação e Agricultura (FAO) (SLINGENBERGH, 2013) adverte que cerca de 70\% das novas doenças que infectaram humanos nas últimas décadas foram de origem animal e que o espalhamento dessas doenças ocorre, entre outros fatores, pelas formas de produção agrícola e animal e pela forma de ocupação e uso dos territórios.

Neste contexto, iniciativas como a One Health, composta por atores da sociedade civil e organizações científicas e profissionais que incentivam estratégias globais para desenvolver a colaboração e a comunicação interdisciplinar quanto aos aspectos dos cuidados de saúde entre humanos, animais e meio ambiente. No entanto, a falta de articulação entre as ciências médicas e a medicina veterinária, entre a pesquisa microbiológica (e clínica) e a epidemiologia, entre todas essas áreas acadêmicas e as ciências sociais, bem como a divisão da vigilância epidemiológica entre o setor da saúde 
e a agricultura/pecuária, de forma independente e desarticulada, tendem a dificultar as ações de vigilância e controle das zoonoses e dos patógenos que cruzam as fronteiras de espécie (GRISOTTI, 2003; MEDITSCH, 2006; SANTOS, 2013).

\section{A leishmaniose visceral canina: uma perspectiva sociopolítica}

Reconhecidas como um importante problema de saúde pública, as leishmanioses representam um conjunto de doenças com amplo espectro clínico e diversidade epidemiológica. A leishmaniose visceral (LV) é uma epidemia que atinge milhares de pessoas no mundo: segundo dados oficiais disponibilizados pela OMS, foram notificados 853.450 casos da doença entre 1998 e 2018. O dado é ainda mais surpreendente quando identificada a grande subnotificação de casos. No Brasil, por exemplo, a taxa de subnotificação de LV se estabelece em torno de $42 \%$ a $45 \%$ (MAIAELKHOURY; CARMO; SOUSA-GOMES; MOTA, 2007). Esse fator, por si só, indica que esta é uma doença negligenciada.

Transmitida por meio da picada do flebótomo, popularmente conhecido como "mosquito-palha", responsável então pela intermediação da contaminação animal à infecção humana (BRASIL, 2014b), a LV pode provocar um estado de debilidade progressiva e até mesmo a morte (ALVARENGA; ESCALDA; COSTA; MONREAL, 2010). O cão é apontado como reservatório desta doença (FALQUETO; FERREIRA, 2005), e o controle do reservatório canino, com inquérito sorológico e eutanásia dos animais infectados, se configura como uma das estratégias de controle atualmente utilizadas, além de aplicação de inseticidas, diagnóstico e tratamento adequado dos casos registrados. Ao mesmo tempo, o controle desses animais por meio da eutanásia se apresenta como um dos temas mais controversos no que tange à sua contribuição para a redução da incidência das leishmanioses, humanas ou caninas (LIMA; GRISOTTI, 2018).

A recomendação da eutanásia, no entanto, tem uma história no Brasil. O Decreto $\mathrm{n}^{\circ} 51.838$, de 14 de março de 1963 apresenta o que viria ser o status quo do combate à LV no Brasil. Dentre as medidas profiláticas estão investigação epidemiológica; inquéritos extensivos para descoberta de cães infectados; eliminação dos animais domésticos doentes (a principal discussão deste artigo); campanhas sistemáticas de controle dos flebótomos nas áreas endêmicas; e tratamento dos casos humanos. $\mathrm{Na}$ época, a doença se restringia principalmente às regiões rurais, sob a tutela do extinto Instituto Nacional de Endemias Rurais.

Em 1984, a OMS já tinha ciência de que havia "poucas comunidades dispostas 
a aceitar que se reduza sem discriminação a população canina"1 (WHO, 1984, p.114, tradução nossa). Porém, nesta época, relatava-se que a redução e a eliminação do número de cachorros de rua ao longo da história poderiam estar associadas à diminuição do número de casos de LV. Como exemplo, a OMS relata o caso da China que, nos anos 1950, examinou mais de 200.000 cães e eliminou centenas, mostrando que tal ação teve uma influência na redução do número de casos humanos.

A OMS afirma ainda que "a eliminação de cachorros selvagens e de rua se justifica por muitos motivos relacionados à saúde, o meio e a conservação. A existência de LVC é uma razão adicional"' (WHO, 1990, p.56, tradução nossa). Embora defensora da prática da eutanásia em cães, errantes ou de estimação, sintomáticos ou soropositivos, a OMS reconhece as particularidades de cada país e/ou região na efetividade do controle.

Embora essa prática pareça efetiva na China, não está claro se funcionou em outros lugares. No Brasil, por exemplo, a LVC aumentou constantemente nos últimos 10 a 20 anos apesar da pulverização de 200.000 casas e da morte de 20.000 cães por ano. Após pesquisas anuais em regiões endêmicas, os cães são sacrificados se suas amostras de sangue forem diagnosticadas como positivas por imunofluorescência. Embora estudos experimentais indiquem que o controle de cães pode reduzir a incidência de Leishmania em cães e crianças, preocupações com os atrasos entre amostragem, diagnóstico e seleção, e falha na redução do número de casos notificados, levaram ao ceticismo quanto à eficácia do programa de controle brasileiro [...]. Dada a seriedade da doença, a falta de vontade dos donos de cães em permitir que seus cães sejam abatidos e a inconsistência dos resultados de ensaios projetados para testar a eficácia, a identificação de estratégias alternativas sustentáveis para reduzir a carga de LVC não são claras $^{3}$ (WHO, 2004, p.74, tradução nossa).

\footnotetext{
1 "There are few communities where indiscriminate dog control is acceptable" (Texto original).

2 "The elimination of stray and feral dogs is justified for many reasons connected with health, the environment and conservation. The existence of ZVL provides additional justification." (Texto original).

3 "Although this practice appears to have been effective in China, it is unclear whether it has worked elsewhere. In Brazil, for example, ZVL has increased steadily during the last 10-20 years despite the spraying of 200000 houses and killing of 20000 dogs per year. Following annual surveys in endemic regions, dogs are culled if their blood samples are diagnosed positive by immunofluorescence. Although experimental trials indicate that dog control may reduce Leishmania incidence in both dogs and children, concerns over the delays between sampling, diagnosis and culling, and a failure to reduce the number of notified cases, have led to scepticism of the effectiveness of the Brazilian control programme [...]. Given the seriousness of the disease, the unwillingness of dog owners to permit their dogs to be culled, and the inconsistent results of trials designed to test the effectiveness of culling, the need to identify alternative sustainable strategies to reduce the burden of ZVL is clear." (Texto original)
} 
As questões sociais envolvendo a relação humano-animal, em especial o valor financeiro, sentimental e prático dos cães, foram consideradas nos documentos da Organização, no entanto, pouco problematizadas no sentido de fomentar o debate e auxiliar nas estratégias para lidar com esse impasse.

Em um informe sobre epidemiologia e controle das leishmanioses por países e territórios, a OMS descreveu características importantes sobre o caso no Brasil (DESJEUX, 1991). Até aquele momento, o foco principal da doença era o Nordeste e a predominância era em ambientes rurais, porém, já naquela época, podíamos ver a incidência em algumas cidades (movimento de urbanização da doença que viria a se tornar muito relevante alguns anos mais tarde). Em alguns locais endêmicos, foi relatada uma situação com mais de $20 \%$ de todos os cães contaminados, porém, em âmbito geral, a taxa de infecção girava em torno de 3\% a 13\% do total de cães (algo compatível com os dados que veremos mais adiante em relação ao caso de Florianópolis-SC). Entre o período de 1979 e 1986, segundo o informe, foram eutanasiados mais de 50.000 cães.

No Manual de Vigilância e Controle da Leishmaniose Visceral, publicado pelo Ministério da Saúde, consta uma recomendação que não deixa qualquer dúvida: “A prática da eutanásia canina é recomendada a todos os animais sororreagentes e/ou com parasitológico positivo" (BRASIL, 2014b, p.66). Além desta, há medidas preventivas como: controle da população canina errante; doação de animais; vacina antileishmaniose visceral canina; uso de telas em canis individuais ou coletivos; e coleiras impregnadas com deltametrina a 4\%. Em relação ao tratamento canino, o Ministério tem uma posição muito clara: "O tratamento de cães não é uma medida recomendada, pois não diminui a importância do cão como reservatório do parasito" (BRASIL, 2014b, p.39).

Entre 2007 e 2009 foram realizados dois fóruns, organizados pelo Ministério da Saúde em conjunto com a Organização Pan-americana de Saúde (OPAS), para tratar especificamente do tratamento de LVC. O documento do I Fórum contraindica o tratamento de cães com LVC e reforça a eutanásia como método eficaz de controle dos reservatórios caninos. A justificativa se dá pela impossibilidade do uso de medicamentos utilizados em humanos, já que isso poderia incorrer em risco de seleção de parasitas resistentes, prejudicando assim o tratamento humano, e por não haver métodos alternativos com eficácia cientificamente comprovada. Esse fórum inclusive resultou na Portaria Interministerial $\mathrm{n}^{\mathrm{o}} 1.426$, de 11 de julho de 2008, que proíbe o tratamento da LVC com produtos de uso humano ou não registrados no Ministério da Agricultura, Pecuária e Abastecimento (MAPA).

Após esse evento e essa portaria, diversas entidades entraram com ações judiciais contra a União alegando que havia estudos e pesquisas que trariam novas 
evidências a respeito do tema. Por esse motivo, solicitou-se a realização de um II Fórum que traria luz a essas novas informações. Então, no dia 01 e 02 de outubro de 2009, na sede da OPAS em Brasília, foi realizado o II Fórum de discussão sobre o tratamento de Leishmaniose Visceral Canina. Após as discussões, o relatório final manteve a posição de não recomendação de tratamentos caninos. Mantiveram-se também os mesmos argumentos, somados ao fato de que os novos estudos realizados entre 2007 e 2009 não apresentavam informações robustas o suficiente para garantir a segurança dos tratamentos para a saúde pública (FÓRUM, 2009).

Ainda em 2007, o MAPA e o Ministério da Saúde publicaram a Instrução Normativa Interministerial (INI) $\mathrm{n}^{\circ} 31$ (BRASIL, 2007) que visava regulamentar a pesquisa, o desenvolvimento, a produção, a avaliação, o registro e a renovação de licenças, de comercialização e de uso de vacina contra a LVC. Além disso, estipulava um prazo de três anos para que as vacinas até então regulamentadas cumprissem todas as fases para nova regulamentação.

Em 2009, o MAPA e o Ministério da Saúde publicaram a Nota de Esclarecimento sobre as vacinas antileishmaniose visceral canina registradas no MAPA. Essa nota estabeleceu que, por conta da inclusão de uma terceira fase no desenvolvimento e na certificação da eficácia e segurança das vacinas pela INI $n^{\circ} 31$, novas vacinas ou vacinas anteriormente registradas no MAPA não deveriam ser utilizadas em saúde pública até que apresentassem os resultados desta terceira fase. Nela são apresentadas também as duas vacinas que estavam registradas antes da publicação da INI n ${ }^{\circ}$ 31, a Leishmune e a Leish-Tec, que ainda teriam de passar por essa nova fase.

A Leishmune havia sido registrada no MAPA segundo o Ato $\mathrm{n}^{\circ} 10$, de 03 de outubro de 2011, sendo a primeira vacina registrada contra a leishmaniose visceral canina do Brasil (CASTRO, 2013) após a INI no 31. Porém, teve sua Licença de Fabricação e Comercialização do produto suspensa pela Nota Técnica $\mathrm{n}^{\circ}$ 038/2014/DFIP/SDA do MAPA (BRASIL, 2014a), que justificou a suspensão devido ao não cumprimento do Regulamento Técnico publicado na INI ${ }^{\circ} 31$, especificamente por não atendido completamente aos requisitos da fase III.

Já a Leish-Tec, pelo contrário, só teve seu registro efetivado em 2013 e ainda se encontra regularizada e licenciada pelo MAPA. O Conselho Regional de Medicina Veterinária do Paraná apresenta esclarecimentos e recomendações quanto ao seu uso.

Os estudos exigidos na IN-31 não preveem a avaliação do impacto do uso desses imunobiológicos na redução da incidência humana de leishmaniose visceral e, portanto, não existe avaliação da vacina quanto a um possível uso como ferramenta de controle da doença em humanos. Desta forma, a vacina Leish-tec está 
recomendada apenas como uma medida de proteção individual para os cães. A vacina deverá ser usada somente em cães assintomáticos com resultados sorológicos negativos para leishmaniose visceral. A vacina não protege cem por cento dos cães, portanto animais vacinados podem adquirir a infecção e tornaremse portadores infectantes para o vetor. A vacinação não é o único instrumento de prevenção desta enfermidade nos cães, portanto, outras medidas devem ser adotadas, tais como: uso de coleiras impregnadas com deltametrina a 4\% manejo ambiental, a fim de alterar as condições do meio que propiciem o estabelecimento de criadouros para formas imaturas do vetor; uso de telas em canis individuais ou coletivos; entre outras. Os animais vacinados que apresentarem sinais clínicos de leishmaniose visceral e reações sorológicas positivas são passíveis das medidas sanitárias vigentes (CONSELHO, 2013).

No V Encontro Nacional de Defesa Sanitária Animal, em 2017, o representante do Ministério da Saúde afirmou que a Leish-Tec era eficaz na prevenção de infecção em cães e que animais vacinados que se infectaram tiveram uma redução na transmissibilidade do parasito para Lutzomyia longipalpis em relação aos animais não vacinados e infectados. Porém, informou que os resultados foram muito imprecisos, não foram estatisticamente significativos e que o estudo não avaliou a efetividade da vacina na redução de casos humanos da doença. Por esse motivo, o uso da vacina foi permitido como proteção individual para os cães e não como uma estratégia de controle da doença em humanos. Afirmou ainda que havia necessidade da realização de um estudo de custo efetividade na redução da incidência humana e que a necessidade de ser aplicadas três doses com intervalo de 21 dias e o alto custo do produto seriam limitações para utilização dessa vacina como estratégia de saúde pública (LIMA JR., 2017).

Documentos da OMS trazem a informação de que pelo menos 50\% dos casos de LVC são assintomáticos. Tendo em vista a baixa efetividade de testes usados no Brasil e o alto índice de cães assintomáticos, muitos animais infectados acabam permanecendo ocultos aos olhos da vigilância sanitária, principalmente naqueles lugares em que não se investe em uma busca ativa. "A ideia seria eliminar todos os cães sintomáticos ou soropositivos; porém, a triagem e eliminação massiva de cães soropositivos não tem demonstrado uma eficácia uniforme em programas de controle (por exemplo, no Brasil)"’4 (WHO, 2010, p.76, tradução nossa). A OMS ressalta que não se deve utilizar medicamentos humanos em animais devido aos riscos e aborda um

\footnotetext{
4 "Ideally, all symptomatic or seropositive dogs should be eliminated; however, screening and mass culling of seropositive dogs has not proved uniformly effective in control programmes (for example, in Brazil)" (Texto original).
} 
problema importante em relação ao tratamento: “Apesar de sua cura clínica, uma grande porcentagem de cães tratados recuperam sua infectividade para os flebótomos alguns meses depois da quimioterapia, escondendo assim o problema epidemiológico da fonte da infecção"5 (WHO, 2010, p.76, tradução nossa). Há uma grande responsabilidade em se fazer essa escolha, pois ao permitir que cães não sejam eutanasiados e sim tratados, a vigilância sobre esse cão deve ser até o fim de sua vida, pois há grandes chances de que ele volte a se tornar um transmissor da doença.

Nesse sentido, há aqui um impasse estabelecido entre a eliminação de cães soropositivos no combate da leishmaniose visceral; as resistências da entrega do animal devido ao valor afetivo atribuído pelo seu proprietário; e as responsabilidades assumidas quanto aos riscos individuais e coletivos. Nossa intenção não é julgar qual posição está correta, mas mostrar que o não reconhecimento dos fatores sociais envolvidos no controle dessa doença tende a gerar efeitos contrários, reduzindo a efetividade dessa política pública, como mostraremos a seguir.

\section{A eutanásia de cães em Florianópolis-SC}

Uma nota técnica da Diretoria de Vigilância Epidemiológica (DIVE) do estado de Santa Catarina (SANTA CATARINA, 2010) estabeleceu a ocorrência de quatro casos de LVC no município de Florianópolis, passando, pela primeira vez, a ser considerado área de transmissão da doença. De 2010 a 2020, 19.065 cães foram examinados, dos quais 686 foram diagnosticados com a doença e 383 foram eutanasiados (Tabela 1). Além da investigação para detectar novos casos e ações educativas com objetivo de prevenir a doença, a DIVE estabeleceu a "realização de eutanásia em 100\% dos cães sororreagentes" (SANTA CATARINA, 2010, p.2). No entanto, os dados abaixo mostram que essa medida não foi cumprida ao longo dos anos.

\footnotetext{
5 "A large percentage of treated dogs recover their infectivity to sandflies a few months after chemotherapy, despite clinical healing, thereby hiding the epidemiological problem of the source of infection" (Texto original).
} 
Tabela 1 - Total de casos retirados dos relatórios das atividades de controle da LVC divulgados pelo CCZ de Florianópolis-SC

\begin{tabular}{lccccc}
\hline & Examinados & Positivos & Negativos & $\begin{array}{c}\text { Aguardando } \\
\text { resultado }\end{array}$ & Eutanasiados \\
\hline Inquérito & 6370 & 320 & 5785 & 170 & 173 \\
$\begin{array}{l}\text { Demanda } \\
\text { espontânea }\end{array}$ & 12695 & 366 & 12019 & 187 & 210 \\
Total & 19065 & 686 & 17804 & 357 & 383 \\
\hline
\end{tabular}

Fonte: Dos autores.

O número de exames realizados (e cães soropositivos detectados) cresceu em 2017 (Gráfico 1), mesmo ano em que foi detectado o primeiro caso de leishmaniose visceral humana.

Gráfico 1 - Total de casos examinados, retirados dos relatórios das atividades da LVC divulgados pelo $\mathrm{CCZ}$ de Florianópolis-SC

TOTAL DE CASOS EXAMINADOS

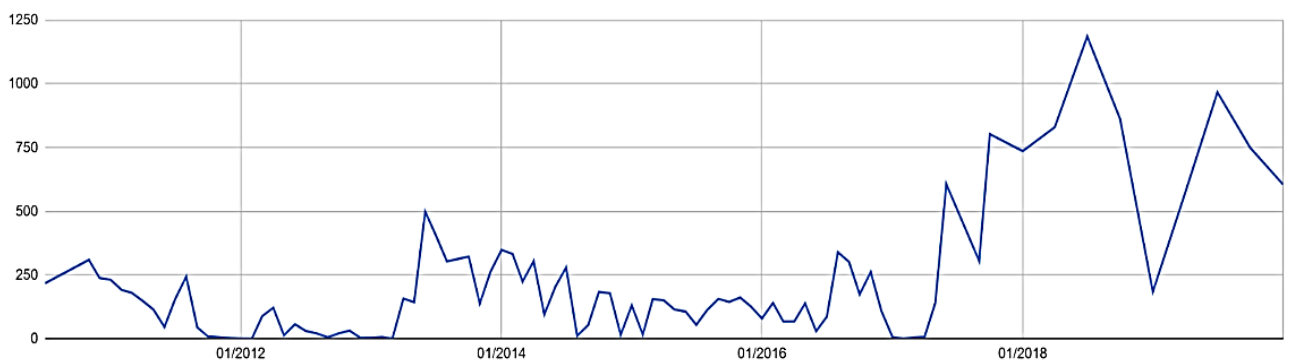

Fonte: Dos autores.

Ao analisar os números de cães positivos ao longo desses 10 anos desta amostra, em conjunto com o número de cães eutanasiados (Gráfico 2), pode-se perceber uma área evidente entre essas duas variáveis, que representam aqueles cães soropositivos que não foram eutanasiados. Além disso, a falta de sincronia histórica das duas variáveis mostra um dos problemas apresentados pela OMS relativo à demora para detecção e eutanásia desses animais. Nesse sentido, nem sempre os cães soropositivos eram eutanasiados no mesmo mês em que eram detectados. Essa lacuna temporal facilita então a transmissão da doença deste cão positivo a outros cães e corrobora com as preocupações da OMS quanto à a ineficácia da adoção desse tipo de medida de controle da leishmaniose visceral no Brasil. Em entrevista, o profissional do $\mathrm{CCZ}$ relatou que alguns proprietários 
de cães, ao saberem da positividade no resultado do exame, mudaram de local residência, perdendo-se, com isso, o rastreamento do caso e possibilitando a dispersão para outros bairros da cidade.

Gráfico 2 - Positivos vs Eutanasiados. Elaborado a partir dos relatórios das atividades da LVCanina divulgados pelo CCZ de Florianópolis-SC

\section{POSITIVOS VS EUTANASIADOS}

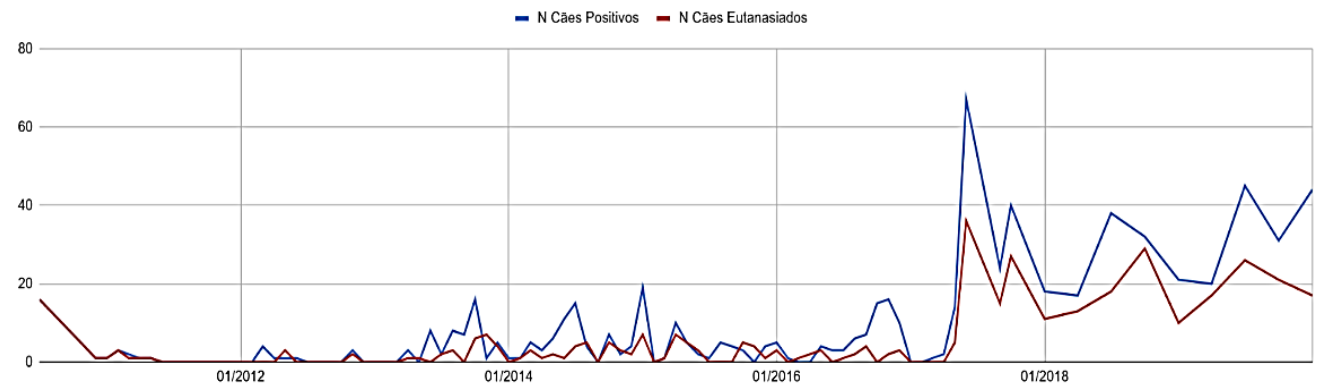

Fonte: Dos autores.

Em alguns momentos nesses 10 anos, a taxa de cães soropositivos por cães examinados (Gráfico 3) alcançou valores muito altos, sendo 36\% em agosto de 2014, $27 \%$ em dezembro de 2014 e $29 \%$ em maio de 2017, superiores aos $20 \%$ de taxa registrados em áreas endêmicas, como no Nordeste entre 1979 e 1986. Porém, esses foram apenas alguns picos, já que a taxa média ao longo desse período se manteve em $3,6 \%$ de cães soropositivos dentre os examinados. Essa taxa sobe, se analisados apenas os últimos anos, para 4,8\% entre maio de 2017 e março de 2020 . Tendo em vista que a leishmaniose visceral não existia (ou era subnotificada) na região Sul, atingir taxas compatíveis com as encontradas no Nordeste, em regiões onde essa doença tem um impacto há mais de 30 anos, indica que a LV de fato se estabeleceu no município de Florianópolis-SC. 
Gráfico 3 - Positivos/Examinados. Elaborado a partir dos relatórios das atividades da LVC divulgados pelo CCZ de Florianópolis-SC

POSITIVOS/EXAMINADOS

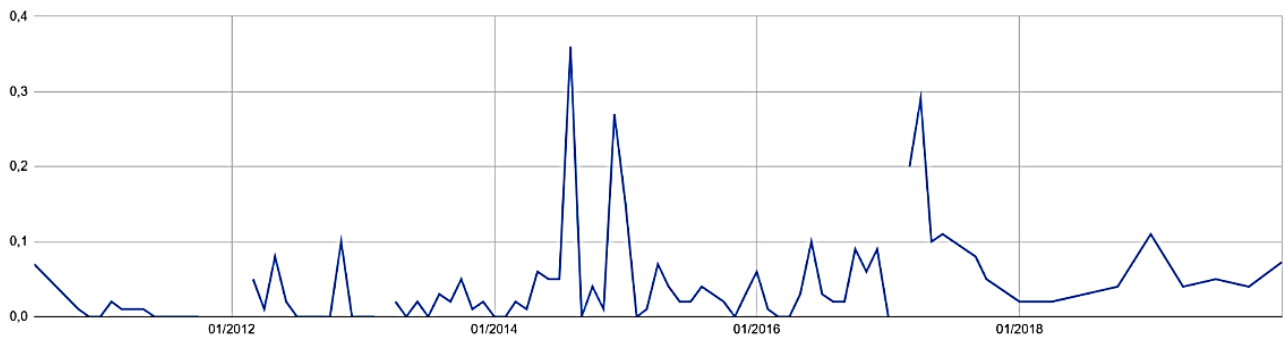

Fonte: Dos autores.

Ao analisar os casos positivos dentre os examinados, percebe-se que quando os exames são feitos via inquérito, a taxa de positividade (positivos/examinados) é muito maior do que via demanda espontânea, tendo uma significância $<0,001$ quando rodado o teste chi-quadrado de Pearson. Isso demonstra que a capacidade de localização de áreas com maiores índices da doença depende mais da busca ativa realizada pela CCZ, através dos inquéritos, do que da espera de que os animais sejam levados espontaneamente pelos seus proprietários até o órgão. Ou seja, uma ação ativa se mostra mais eficiente para localizar cães soropositivos do que uma ação passiva.

Gráfico 4 - Positivos/Examinados (por inquérito ou demanda espontânea). Elaborado a partir dos relatórios das atividades da LVC divulgados pelo CCZ de Florianópolis-SC

\section{POSITIVOS/EXAMINADOS}

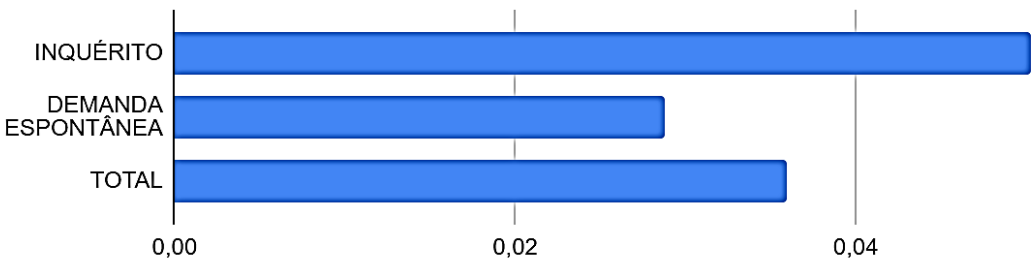

Fonte: Dos autores.

Outra questão interessante é que, ao longo de todos esses anos, as atividades divulgadas pela CCZ de Florianópolis-SC se resumiram aos informes de ações preventivas a serem tomadas pela população: a distribuição em massa de coleiras repelentes e a testagem de cães, seguidas, em alguns casos, da eutanásia dos animais após o consentimento do seu tutor. Durante esses 10 anos, apenas $56 \%$ dos cães 
diagnosticados como positivos no município foram, de fato, eutanasiados. As dificuldades para a entrega do cão também ocorreram em um município endêmico do estado de Minas Gerais onde os autores analisaram a relação humano-animal em um bairro de maior soroprevalência canina de leishmaniose e investigaram as repercussões sociais percebidas na entrega do animal para eutanásia pelo serviço de controle de zoonoses (LIMA; GRISOTTI, 2018).

Os dados mostram que apesar de a eutanásia ser uma questão central dentro do plano de contingência do município de Florianópolis-SC, o fato dela ser uma escolha e decisão dos proprietários dos cães limita a efetividade da ação de saúde pública:

Tinha a questão da polêmica da eutanásia. Era recomendado. A gente queria que a população se conscientizasse do risco à saúde pública, mas não que fosse uma obrigação do governo: 'tem que fazer a eutanásia'. Então, a gente tentou muito conversar com o proprietário, mostrar os riscos, para tentar ser uma forma espontânea, voluntariamente 'vou entregar o cão porque realmente não tem o que fazer’. (Entrevista com funcionário da CCZ).

Apesar de afirmar que foi realizado um trabalho intensivo de inquérito para detecção de cães soropositivos (que se comprova pelos dados mensais apresentados no site do CCZ) e de se utilizar de testes de triagem rápidos ("em 10 minutos fica pronto", segundo o entrevistado), a centralidade das ações do município na detecção e eutanásia de cães se mostrou não efetiva no combate à doença.

A pessoa pode autorizar ou negar. Nos dois casos ele vai assinar uma ficha, um documento. Então se ela autorizar, a gente faz o procedimento aqui. [...] Se a pessoa se recusar a fazer, esse cão vai ficar com ela. A gente orienta para que tome todas as medidas possíveis [...]. A gente faz um relatório dos cães positivos que têm recusa e encaminha para vigilância sanitária. A vigilância sanitária vai abrir um processo administrativo sanitário e vai autuar ele segundo o código de vigilância em saúde. [...] Essa pessoa pode pagar o auto de infração, resolver entregar, como ela pode entrar na justiça, isso vai até o Ministério Público (Entrevista com funcionário da CCZ).

Nesse sentido, há aqui a judicialização de uma questão que envolve o conflito entre cultura (e valores sociais) e a racionalidade epidemiológica. Do ponto de vista da saúde pública, mesmo que após todo esse processo jurídico o cão seja eutanasiado, há grandes chances de ele já haver transmitido a doença para outro cão que não havia sido detectado anteriormente. Por outro lado, em uma democracia, a justiça é um pilar 
fundamental e as pessoas têm o direito de recorrer das ações estatais que não consideram justas ou adequadas. Há aqui um impasse entre a ação mais adequada encontrada pelo setor público e especialistas para controlar a doença de forma efetiva e o fator social associado ao valor do cão e à movimentação de organizações, setores profissionais e pessoas físicas contra as ações do Estado, se utilizando inclusive do aparato legal para enfrentar esse contexto.

Teve problema justamente por isso, a gente via que pessoas que tinham um poder aquisitivo um pouco mais baixo colaboravam muito mais, procuravam entender a doença e se preocupavam mais do que pessoas que tinham certo nível de instrução e também um poder aquisitivo maior. Então a gente teve uma situação em um condomínio da Lagoa em que o proprietário de um cão positivo era médico e ele se recusou a fazer, disse que ia tratar, e que ia fazer tudo que era possível, não ia entregar o cão. Não se preocupou com a questão da saúde pública. Assim, foi interessante porque, nesse caso, houve uma pressão do próprio condomínio, porque a gente teve que fazer investigação. Em nenhum momento a gente fala pra população qual é o proprietário que tem o cão positivo, a gente toma esse cuidado ético. Até para não ter um conflito, mas a gente fala 'olha, nessa área tem um cão positivo, a gente tá fazendo a investigação, vamos coletar o sangue do seu animal para verificar se esse animal é positivo ou não'. E a gente fez todo esse trabalho ali na comunidade e, depois, a pessoa acaba sabendo, 'ah, foi o fulano de tal que teve o cão positivo', e a própria comunidade daquele condomínio, daquela região, começou a pressionar ele. Ele entregou o animal depois disso, passaram alguns meses [...]. E ele se mudou de lá. Não aguentou a pressão e saiu. (Entrevista com funcionário da $\mathrm{CCZ}$ ).

Até aqui mostramos as relações estabelecidas entre os órgãos públicos de vigilância em zoonoses e os proprietários de cães. Mas há outros atores que entram em cena: os meios de comunicação, as organizações não governamentais (ONGs) de defesa dos animais e os discursos de veterinários de clínicas privadas, complexificando os aparatos sociotécnicos utilizados para o controle da LVC.

A imprensa de Florianópolis-SC, em sua maior parte, teve um papel importante na divulgação de informações sobre a doença e medidas de prevenção. Porém, em alguns casos, ao tratar especificamente sobre a questão da eutanásia, as notícias emitiam posições deliberadas, como exemplificado pelo título da reportagem publicada pelo programa Balanço Geral em 24 de outubro de 2017: "Eutanásia não é única saída para leishmaniose". Nesta reportagem discute-se o motivo de sacrificar animais em plena modernidade, já que existiriam tratamentos e vacinas para a doença. Porém, ao abordar 
esses tratamentos e vacinas, na maioria das vezes não são problematizadas tais medidas.

A posição de ONGs ligadas à defesa dos animais e os discursos de médicos veterinários de clínicas privadas geralmente são colocados em primeiro plano em detrimento do discurso médico-epidemiológico sobre a doença em humanos. O pedido de realização do II Fórum sobre o tratamento da Leishmaniose Visceral, que ocorreu em 2009, também partiu de profissionais liberais veterinários, demonstrando o forte interesse dessa classe na temática:

A proibição do tratamento da LVC vem sendo atualmente contestada por profissionais liberais que atuam em estabelecimentos veterinários, portanto, após a publicação desta Portaria ( PI n $^{\circ} 31$ do MAPA e do Ministério da Saúde), ações judiciais vêm sendo impetradas contra a União. Na Ação Civil Pública movida no estado de Minas Gerais, durante a audiência de conciliação/justificação, foram apresentadas pelos requerentes informações de que estudos recentes trariam novas evidências acerca do tema. (FÓRUM, 2009, p.2).

Um ator social importante percebido ao longo da pesquisa é representado pela classe dos médicos veterinários de clínicas privadas. A presença desse profissional no pedido de realização de um segundo fórum para rever as normas de tratamento animal e eutanásia e o constante aparecimento em reportagens, ocupando o lugar da fala técnica de sua área de atuação em contraposição ao discurso dos epidemiologistas, demonstra seu protagonismo para falar em nome dos cães, mas também em nome dos interesses ligados à sua atuação profissional, tendo em vista que os tratamentos são geralmente de alto custo e devem ser aplicados de forma contínua ao longo de toda a vida do animal. A eutanásia de animais parece ser ao mesmo tempo a "eutanásia" de um grande mercado consumidor, seja do tratamento em si para a doença ou dos produtos que esses animais consomem. A morte de animais em massa parece não ser boa para os negócios:

Infelizmente poucos veterinários notificam. É um problema também que a gente tem. Colegas nossos, ou não notificam porque não tem muita noção de saúde pública, ou porque têm uma visão oportunista financeira, ou porque acreditam no tratamento, têm aquela visão mais clínica, da questão do tratamento, de funcionar, enfim. É importante deixar claro que não se tem medicamentos já provados pelo Ministério da Agricultura para Leishmaniose Visceral (Entrevista com funcionário da CCZ).

Há uma forte pressão por parte de ONGs, veterinários de clínicas privadas e suas associações profissionais aliadas a pessoas físicas não organizadas que não querem 
ter seus cães eutanasiados. Contudo, é importante destacar que as posições dos médicos veterinários não são homogêneas e variam de acordo com seu lugar de ocupação profissional, como pode ser observado na declaração de uma veterinária que trabalha no $\mathrm{CCZ}$, ao relatar as ameaças que vinha sofrendo ao fazer essas investigações via inquérito:

Eu queria só deixar claro que a gente teve que parar esse procedimento [inquérito sorológico] porque a gente sofreu ameaças pela internet e de algumas pessoas. Então a gente gostaria de conscientizar as pessoas, a importância do nosso trabalho. Que a gente não vai lá com o intuito de coletar o sangue do cão e ir embora. Que a gente vai parar orientar. Então essa população em área de risco precisa da nossa orientação de prevenção, dos sintomas nas pessoas e nos cães [...] (SERVIDORES, 2017).

Inclusive, nesta mesma reportagem, a servidora do órgão relata qual o encaminhamento a partir dos resultados positivos nos testes:

A orientação do Ministério da Saúde ainda é a eutanásia do cão. Mas, desde o final de 2016 foi liberada a comercialização de um medicamento para tratamento. Então o proprietário, ele sempre teve, a gente só faz eutanásia quando autorizado, ele sempre teve e agora tem o direito de fazer o tratamento. Esse tratamento não cura o animal, mas o animal fica clinicamente bem, então a gente só recomenda que só utilize a coleira repelente ou algum produto repelente porque ele ainda vai ter $\mathrm{o}$ protozoário causador da doença (SERVIDORES, 2017).

Como se pode perceber nessa entrevista feita pelo G1, a eutanásia se torna optativa e a servidora não informou sobre os procedimentos subsequentes, declarando que "a gente só recomenda que se utilize coleira repelente ou algum produto repelente", medida que parece insuficiente quando se pensa no combate de uma epidemia como a leishmaniose visceral.

O papel dos veterinários nesse tipo de reportagem é, na maioria das vezes, o de "especialista" ou "técnico"; geralmente a leishmaniose visceral é tratada apenas como uma doença animal, não sendo deixado claro que a eutanásia é justificada nos cães principalmente pelo fato de ser uma doença que pode atingir seres humanos e que, em caso de não tratamento, possui uma alta taxa de letalidade. Em 2018, em outra reportagem do Balanço Geral, um veterinário de clínica privada diz que as medidas adotadas em relação à eutanásia não proveem de recomendações técnicas, diferente do que foi encontrado em diversos documentos públicos da OMS, OPAS e Ministério da 
Saúde. "Então o que a gente questiona é o gasto do dinheiro público numa política que sabidamente não tem recomendação técnica" (DIREITOS, 2018).

Nessa reportagem, gravada sob o título de "Direitos dos animais é assunto de seminário realizado em Florianópolis", outra questão importante relatada, mas descrita de forma sucinta, é o alto custo do tratamento que o dono do animal teria que desembolsar. "A diretoria de bem-estar animal disse que tratar os animais custaria 10.000 reais e a eutanásia seria a melhor forma de evitar que o mosquito picasse os cães e transmitisse a doença para as pessoas" (DIREITOS, 2018). Enquanto isso era narrado, apareciam imagens do dono do animal brincando e alimentando um cão aparentemente saudável.

Além dessas duas figuras (o médico veterinário e o dono do cachorro ao qual a eutanásia foi recomendada), há também a presença, na mesma reportagem, do terceiro pilar, o representante de alguma organização de defesa dos animais. "A nossa principal dificuldade é exatamente acionar as autoridades, que isso se transforme num inquérito, e que algumas pessoas, que estão à margem da lei, sejam penalizadas e identificadas" (DIREITOS, 2018). A partir dessa fala vê-se novamente a questão da judicialização e, de forma mais enfática, é reportada aqui a ideia de que as ações realizadas pela CCZ são ações "à margem da lei".

Essa tríade de atores sociais (donos dos animais, veterinários de clínicas privadas e representantes de organização de defesa dos animais) é constantemente apresentada na composição de reportagens que abordam a questão da eutanásia. A ausência de figuras representantes do CCZ e de especialistas em epidemiologia é latente, inclusive na matéria do Balanço Geral de 2018 citada anteriormente.

Especificamente acerca da judicialização, outra matéria, também do programa Balanço Geral, é bastante elucidativa em relação aos problemas que podem advir de um jornalismo parcial. O título da reportagem já explicita a desinformação que ela viria a promover: "Justiça suspende eutanásia em cães diagnosticados com leishmaniose em Florianópolis" (JUSTIÇA, 2018). Ao afirmar que a justiça proibiu a eutanásia de cães em Santa Catarina tem-se a ideia de que esta foi proibida de forma geral no estado, ou seja, toda e qualquer eutanásia animal foi proibida, o que de fato não ocorreu. Além do título sensacionalista, a primeira frase do apresentador também conduz a interpretações errôneas: "A justiça de Santa Catarina determinou a suspensão do processo de eutanásia de cães na capital" (JUSTIÇA, 2018). O que de fato aconteceu foi um caso específico: a decisão de um juiz de suspender a eutanásia dos cães de um morador do Saco dos Limões após a alegação deste de que nem todos os seus cães estavam com a doença. Um representante do CCZ ainda afirmou: 
a prefeitura de Florianópolis é uma das únicas no Brasil que abriu essa margem, deliberada por salvas situações, por diversos representantes de ONGs, professores da universidade, o próprio prefeito. Então a gente deliberou que tudo aquilo que for optado pelo tutor deve ser de ciência dele como autorização dele. A gente não faz nada fora a autorização do tutor (JUSTIÇA, 2018).

Percebe-se, então, que a imprensa de Florianópolis-SC concentrou o debate no discurso de defesa dos animais, mostrando a força e a influência desses atores sociais, e omitiu aspectos epidemiológicos importantes para o combate a leishmaniose visceral. Também não promoveu um debate sobre o controle dos vetores (flebótomos), tão ou mais importante do que os reservatórios (cães). Os impasses gerados pelas diferentes posições e interesses em jogo, a falta de articulação entre os atores sociais e falta de uma campanha que leve em consideração os aspectos sociais envolvidos na questão geraram um efeito contraprodutivo (ampliação dos focos de transmissão):

Tiveram outras situações que a gente acabou descobrindo depois de fazer inquéritos. A gente descobriu que o cão era da lagoa, a pessoa se mudou e levou o cão para outro bairro. Teve no Rio Vermelho, o animal positivo, esse tá em processo. [...] Tiveram pessoas que saíram de Florianópolis, também. Depois que a gente começou a descobrir isso. Tinham o cão positivo, assinaram o termo de recusa, e tava com a vigilância em processo. A gente descobriu que teve um que foi para Urubici. A gente teve que notificar a vigilância em saúde de Urubici. Teve outra que foi para São José. Então a gente teve que fazer esse trabalho, os animais talvez até estejam lá (Entrevista com funcionário da CCZ).

Iniciamos este artigo com a frase "Deçue par les humanais, jamais pour mon chien”, escrita na lápide no cemitério de cães em Paris; finalizamos com a declaração do profissional da CCZ relatando o caso de uma pessoa que, em nome do amor pelo cachorro, modificou a própria vida para manter a vida de seu animal:

Tem casos de pessoas que vieram de outros locais, que trouxeram cães, de outras localidades endêmicas, se mudaram para Florianópolis. A pessoa fugiu porque não queria fazer a eutanásia. A gente fez um inquérito sorológico amostral em Carianos. E a gente conversou com os moradores que eram de Dourados/MS, e os cães eram negativos, bem tratados e tal. Eles falaram que se mudaram de lá, o motivo foi 'a gente se mudou para Florianópolis porque lá tinha muito caso de leishmaniose visceral canina, a gente ama cachorro e a gente não quer que eles sejam infectados e nem mortos' (Entrevista com funcionário da CCZ). 
Obviamente essa pessoa se mudou para Florianópolis-SC antes da cidade reportar os primeiros casos. Contudo, esse exemplo demonstra a força da noção de família multiespécie e a necessidade de políticas públicas que levem seriamente em conta os fatores sociais e afetivos no debate sobre o controle da doença no Brasil.

\section{Conclusão}

Os resultados desta pesquisa apontam os limites das ações preconizadas pelos órgãos públicos de vigilância em zoonoses, entre elas a eutanásia dos animais positivos para LVC, em função da subestimação do valor social e simbólico que o cão representa para o seu proprietário; da escolha do tratamento como medida de controle da doença (e de sua ineficácia, caso não for feito ao longo de toda a vida do cão); dos altos custos do tratamento e da não comprovação de sua eficácia; e do custo-benefício de vacinas antileishmaniose como medida de saúde pública.

Os impasses gerados pelas diferentes posições e interesses em jogo, a falta de articulação entre os atores sociais e a falta de uma campanha de comunicação pública que leve em consideração os aspectos sociais envolvidos na questão geraram um efeito contraprodutivo nas ações e políticas públicas de controle da doença. Tais aspectos, somados, têm influenciado a ampliação dos focos de transmissão, tornando a leishmaniose visceral uma doença negligenciada e que vem matando muitas pessoas e animais ao longo de quase um século no Brasil.

O controle da leishmaniose visceral no país se concentra no reservatório (o cão), ao passo que medidas de controle dos vetores (flebótomos) são incipientes e desarticuladas. Por focar apenas no reservatório, a CCZ tem preconizado a eutanásia optativa dos cães soropositivos. Como vimos no artigo, a entrega espontânea ou por inquérito é limitada em função da relação afetiva com os animais (o que caracterizamos enquanto família multiespécie).

Quando clínicas veterinárias privadas sugerem o tratamento, o sistema de controle de zoonoses deve desenvolver estratégias muito mais profundas de vigilância desses cães a fim de garantir que os donos estejam cumprindo com todas as etapas do tratamento e que os animais estejam sendo acompanhados por médicos veterinários para que não venham a se tornar novamente transmissores da doença. Assim como alguns grupos e pessoas físicas vêm utilizando de meios legais para defender suas posições, que os órgãos públicos também se utilizem desses meios para defender a saúde pública dos cidadãos. Ou seja, garantir o registro, a vigilância sistemática de casos e fomento do papel dos médicos veterinários enquanto agentes de saúde pública para o controle da 
epidemia na região.

Uma das lições da pandemia de Covid-19 é a necessidade de reativação dos dispositivos de antecipação dos riscos de epidemias. Isso exige a intensificação e/ou reformulação da rede sociotécnica envolvida no controle das zoonoses. Sistemas de rastreabilidade sistemática e contínua dos cães (com donos ou errantes) e intensificação do sistema de vigilância epidemiológica de controle de vetores, aliados às campanhas de saúde pública que discutam os vários fatores socioepidemiológicos deverão fazer parte, de forma mais ativa, nas agendas das políticas públicas em saúde.

Nesse sentido, é fundamental o debate público entre as posições dos profissionais de controle das zoonoses, dos veterinários de clínicas privadas, dos epidemiologistas, dos pesquisadores, das organizações de defesa animal e dos proprietários de cães, juntamente com meios de comunicação que consigam traduzir o debate em sua complexidade para expandi-lo à sociedade. As ciências sociais possuem ferramentas teóricas e metodológicas que poderiam contribuir com esse debate.

\section{BETWEEN LOVE TO ANIMALS AND PUBLIC HEALTH: SOCIOLOGICAL REFLECTIONS ON CANINE VISCERAL LEISHMANIOSIS}

ABSTRACT: Animals have always been part of human societies, whether as a source of food, as sacred entities, as companies or as goods. Among the strands of studies on human and non-human animal relations, this article focuses on an aspect little investigated by the social sciences: the social dimension of policies to control diseases transmitted between humans and animals (zoonotic diseases). We analyzed the controversies and conflicts which occur between the socio-technical measures adopted by the epidemiological surveillance services for the control of this disease and the meanings attributed to this control by zoonoses surveillance professionals and the media, taking as a case study the public actions of control of canine visceral leishmaniasis developed in Florianópolis, SC, Brazil, between 2010 and 2020. The low effectiveness of public control policies is related to the lack of coordination between epidemiological and social factors (related to multi-species families) in preventive campaigns.

KEYWORDS: Multi-species families. Canine visceral leishmaniasis. Health surveillance. Human and animal health. 


\section{ENTRE EL AMOR AL ANIMAL Y LA SALUD PÚBLICA: REFLEXIONES SOCIOLÓGICAS SOBRE LA LEISHMANIOSIS VISCERAL CANINA}

RESUMEN: Los animales siempre han formado parte de las sociedades humanas, ya sea como fuente de alimento, como entidades sagradas, como empresas o como mercancias. Entre las vertientes de los estudios sobre las relaciones entre los seres humanos y los animales no humanos, este artículo se centra en un aspecto poco investigado por las ciencias sociales: la dimensión social de las políticas de control de las enfermedades transmitidas entre los seres humanos y los animales (enfermedades zoonóticas). Analizamos las controversias y conflictos que se producen entre las medidas socio-técnicas adoptadas por los servicios de vigilancia epidemiológica para el control de estas enfermedades y los significados atribuidos a este control por los profesionales de la vigilancia de las zoonosis y los medios de comunicación, tomando como caso de estudio las acciones públicas para el control de la leishmaniosis visceral canina desarrolladas en Florianópolis entre 2010 y 2020. La baja efectividad de las políticas de control público está relacionada con la falta de articulación entre los factores epidemiológicos y sociales (relacionados con las familias multiespecies) en las campañas de prevención.

PALABRAS CLAVE: Familias multiespecies. Leishmaniosis visceral canina. Vigilancia sanitaria. Salud humana y animal.

Agradecimentos

Os pesquisadores agradecem ao CNPq pelo auxílio financeiro na execução do projeto de pesquisa.

\section{REFERÊNCIAS}

ÁVILA-PIRES, F. D. Ecologia. In: COURA, J. R. (org.). Dinâmica das doenças infecciosas e parasitárias. Rio de Janeiro: Guanabara Koogan; 2005. p. 53-64. 
ALVARENGA, D. G.; ESCALDA, P. M. F.; COSTA, A. S. V.; MONREAL, M. T. D. Leishmaniose visceral: estudo retrospectivo de fatores associados à letalidade. Rev. Soc. Bras. Med. Trop., Uberaba, v. 43, n. 2, p. 194-197, 2010.

BATESON, G. Steps to an ecology of mind: collected essays in anthropology, psychuatry, evolution, and epistemology. Northvale: Aronson, 1987.

BRASIL. Decreto no 51.838, de 14 de março de 1963. Brasília, DF: Diário Ofícial da União, 18 de março de 1963. Seção 1, p. 2865.

BRASIL. Ministério da Agricultura, Pecuária e Abastecimento. Ministério da Saúde. Instrução Normativa Interministerial No 31, de 9 de julho de 2007. Brasília, DF, Diário Oficial da União n ${ }^{\circ} .131,10$ de julho de 2007. Seção I, p. 1.

BRASIL. Ministério da Agricultura, Pecuária e Abastecimento. Nota Técnica $\mathbf{N}^{\mathbf{0}}$ 038/2014/DFIP/SDA. Brasília, 2014a.

BRASIL. Ministério da Saúde. Secretaria de Vigilância em Saúde. Departamento de Vigilância Epidemiológica. Manual de vigilância e controle da leishmaniose viscer Brasília: Ministério da Saúde, 2014b.

BRASIL. Ministério da Saúde. Ministério da Agricultura, Pecuária e Abastecimento. Nota de Esclarecimento sobre as vacinas Antileishmaniose Visceral Canina registradas no MAPA. Brasília, 03 maio 2009.

BRASIL. Ministério da Saúde. Ministério da Agricultura, Pecuária e Abastecimento. Portaria Interministerial $\mathbf{n}^{\mathbf{0}}$ 1.426, de 11 de julho de 2008. Brasília, DF, Diário Oficial da União $n^{\circ} .133,14$ de julho de 2008. Seção 1, p. 37.

CASTRO, V. F. Análise do cenário técnico-científico mundial: um estudo de caso em leishmaniose. 2013. Dissertação (Mestrado Profissional em Propriedade Intelectual e Inovação), Academia de Propriedade Intelectual, Inovação e Desenvolvimento, Rio de Janeiro, 2013.

COLLIER, S. J.; LAKOFF, A.; RABINOW, P. Biosecurity: towards an anthropology of the contemporary. Anthropology Today, v. 20, n. 5, 2004.

CONSELHO REGIONAL DE MEDICINA VETERINÁRIA DO PARANÁ. MAPA e Ministério da Saúde liberam vacina Leish-Tec com recomendações para uso. CRMV/PR, 09 maio 2013. Disponível em: https://www.crmv-pr.org.br/noticiasView/3673_MAPA-eMinisterio-da-Saude-liberam-vacina-Leish-tec-com-recomendacoes-para-uso.html. Acesso em: 01 jun. 2020.

CRAWFORD, D. H. Deadly companions: how microbes shaped our history. New York: Oxford University Press, 2007. 
DESCOLA, P. Par-delà nature et culture. Paris: Éditions Gallimard, 2003.

DESCOLA, P. L'ecologie des autres. L'anthropologie et la question de la nature. Éditions Quae: Versailles, 2011

DESJEUX, P. Information on the epidemiology and control of the leishmaniases by country or territory. Geneva: World Health Organization, 1991.

DIREITOS dos animais é assunto de seminário realizado em Florianópolis. Balanço Geral Florianópolis, 2018. 1 vídeo (3min25). Disponível em:

https://www.youtube.com/watch?v=82BjTsn_s9c\&feature=youtu.be. Acesso em: 29 set. 2020.

ELIAS, N. Introdução à sociologia. Lisboa: Edições 70, 1999.

EUTANÁSIA não é única saída para leishmaniose. Balanço Geral Florianópolis, 2017. 1 vídeo (3min48). Disponível em:

https://www.youtube.com/watch?v=T3uWJsBrfA0\&feature=youtu.be. Acesso em: 29 set. 2020 .

FALQUETO, A.; FERREIRA, A. L. Reservatórios extra-humanos do complexo leishmânia e dinâmica de transmissão da infecção ao homem. In: COURA, J. R. (org.). Dinâmica das doenças infecciosas e parasitárias. Rio de Janeiro: Guanabara Koogan, 2005. p. 739-752.

FÓRUM DE DISCUSSÃO SOBRE O TRATAMENTO DE LEISHMANIOSE VISCERAL CANINA (LVC), 2., 2009, Brasília/DF. Relatório final. Brasília: Secretaria de Vigilância em Saúde, 2009.

GAEDTKE, K. M. “Quem não tem filho caça com cão": animais de estimação e as configurações sociais de cuidado e afeto. 2017. Tese (Doutorado em Sociologia Política), Universidade Federal de Santa Catarina, Florianópolis, 2017.

GOFFMANN, E. Frame analysis: an essay on the organization of experience. Boston: Northeastern University Press, 1986.

GRISOTTI, M. Saúde e meio ambiente: a construção médica e popular de uma doença infecciosa emergente. 2003. Tese (Doutorado em Sociologia), Universidade de São Paulo, São Paulo, 2003.

INGOLD, T. Evolution in four dimensions: genetic, epigenetic, behavioral, and symbolic variation in the history of life. Cambridge, Mass.: MIT Press, 2005.

INGOLD, T. Humanidade e animalidade. Rev. bras. Ci. Soc., São Paulo, v. 10, n. 28, p. 39-53, 1995.

INGOLD, T. The perception of the environment: essays on livelihood, dwelling and skill. Londres: Routledge, 2000. 
JUSTIÇA suspende eutanásia em cães diagnosticados com leishmaniose em Florianópolis. Balanço Geral Florianópolis, 2018. 1 vídeo (3min53). Disponível em:

https://www.youtube.com/watch?v=3tNrqRXC71E. Acesso em: 29 set. 2020.

KECK, F. Les sentinelles des pandémies: chasseurs de virus et observateurs d'oiseaux aux frontières de la Chine. Bruxelas: Zones sensibles, 2020.

LIMA JR., F. E. F. Leishmaniose: vacina, tratamento ou sacrifício animal como estratégia de saúde única? In: ENCONTRO NACIONAL DE DEFESA SANITÁRIA ANIMAL ENDESA, 5, 2017, Belém/PA. Brasília: MAPA, 2017.

LIMA, C. C.; GRISOTTI, M. Relação humano-animal e leishmaniose: repercussões no cotidiano de indivíduos inseridos em região endêmica. Saúde Soc., v. 27, n. 4, p.1261-69, 2018. Disponível em: https://www.scielo.br/scielo.php?script=sci_abstract\&pid=S0104$12902018000401261 \& \operatorname{lng}=$ pt\&nrm=iso_Acesso em: 29 set. 2020.

MAIA-ELKHOURY, A. N. S.; CARMO, E. H.; SOUSA-GOMES, M. L.; MOTA, E. Análise dos registros de leishmaniose visceral pelo método de captura-recaptura. Rev. Saúde Pública, São Paulo, v.41, n. 6, p.931-37, 2007.

MEDITSCH, R. G. M. O médico veterinário, as zoonoses e a Saúde Pública: um estudo com profissionais e clientes de clínicas de pequenos animais em Florianópolis, SC, Brasil. 2006.

Dissertação (Mestrado em Saúde Pública), Universidade Federal de Santa Catarina, Florianópolis, 2006.

PITROU, P. Uma antropologia além de natureza e cultura? MANA 21(1), p.181-194, 2015.

ROCK, M.; MYKHALOVSKIY, E; SCHLICH, T. People, other animals and health knowledges: towards a research agenda. Soc. Sci. Med., v. 64, n. 9, p.1970-6, 2007.

SANTA CATARINA. Secretaria de Estado da Saúde. Gerência de Controle de Zoonoses. Nota Técnica no . 007/2010/DIVE/SES. Diretoria de Vigilância Epidemiológica/SES/SC, 16 ago. 2010 .

SANTOS, C. A. O Brasil e o mercado internacional de carne bovina no contexto de doenças infecciosas emergentes: uma análise sociopolítica dos programas de sanidade animal e de normativas de segurança. 2013. Tese (Doutorado em Sociologia Política), Universidade Federal de Santa Catarina, Florianópolis, 2013.

SERVIDORES dizem ter sofrido ameaças durante orientação sobre a leishmaniose em Florianópolis. G1 SC, 18 dez. 2017. Disponível em: https://g1.globo.com/sc/santacatarina/noticia/servidores-dizem-ter-sofrido-ameacas-durante-orientacao-sobre-aleishmaniose-em-florianopolis.ghtml. Acesso em: 01 jun. 2020.

SLINGENBERGH, J. World Livestock 2013, Changing disease landscapes. Food and Agriculture Organization of the United Nations (FAO) Report. Rome, 2013. 
WORLD HEALTH ORGANIZATION - WHO. Control de las Leishmaniasis: Informe de una reunión del Comité de Expertos de la OMS sobre el Control de las Leishmaniasis, Ginebra, 22 a 26 de marzo de 2010. Geneva: WHO, 2010.

WORLD HEALTH ORGANIZATION - WHO. Report of the Scientific Working Group meeting on Leishmaniasis: Geneva, 2-4 February, 2004. Geneva: WHO, 2004.

WORLD HEALTH ORGANIZATION - WHO. Control of the leishmaniases: report of a WHO Expert Committee. Geneva: WHO, 1990.

WORLD HEALTH ORGANIZATION - WHO. Las leishmaniases: report of a WHO expert committee. Geneva: WHO, 1984.

Recebido em 30/08/2020.

Aprovado em 03/09/2020. 